\title{
Thermal Management of Electronics Devices with PCMs filled Pin-fin Heat Sinks: A Comparison
}

\author{
Adeel Arshad ${ }^{1}$, Hafiz Muhammad Ali ${ }^{2 *}$, Mark Jabbal ${ }^{1}$, P.G. Verdin ${ }^{3}$ \\ ${ }^{1}$ Fluids \& Thermal Engineering (FLUTE) Research Group, Faculty of Engineering, University of \\ Nottingham, Nottingham NG7 2RD, UK \\ ${ }^{2}$ Department of Mechanical Engineering, University of Engineering and Technology, Taxila, Pakistan \\ ${ }^{3}$ Energy \& Power Theme, Cranfield University, Cranfield MK43 OAL, UK \\ *h.m.ali@uettaxila.edu.pk
}

\begin{abstract}
The present paper covers the comparison of two different configurations (square and circular) pinfin heat sinks embedded with two different phase change materials (PCMs) namely paraffin wax and n-eicosane having different thermo-physical properties were carried out for passive cooling of electronic devices. The pin-fins, acting as thermal conductivity enhancers (TCEs), of $2 \mathrm{~mm}$ square and $3 \mathrm{~mm}$ circular fin thickness of constant volume fraction of $9 \%$ are chosen and input heat fluxes from $1.2 \mathrm{~kW} / \mathrm{m}^{2}$ to $3.2 \mathrm{~kW} / \mathrm{m}^{2}$ with an increment of $0.4 \mathrm{~kW} / \mathrm{m}^{2}$ are provided. Two different critical set point temperatures (SPTs) $45^{\circ} \mathrm{C}$ and $65^{\circ} \mathrm{C}$ are chosen to explore the thermal performance in terms of enhancement ratios, enhancement in operation time, latent heating phase duration, thermal capacity and conductance. The results show that $3 \mathrm{~mm}$ diameter of circular pinfins has the best thermal performance in passive thermal management of electronic devices.
\end{abstract}

\section{Keywords:}

Phase Change Materials (PCMs), Thermal Conductivity Enhancers (TCEs), pin-fin Heat Sinks, paraffin wax, n-eicosane, Set Point Temperatures (SPTs)

\section{Nomenclature}




$\begin{array}{ll}\text { SPT } & \text { Set Point Temperature } \\ \text { TCE } & \text { Thermal Conductivity Enhancer } \\ \text { PCMs } & \text { Phase Change Materials } \\ \text { LHSU } & \text { latent heat storage unit } \\ G & \text { Thermal conductance }(\mathrm{W} / \mathrm{K}) \\ T_{m} & \text { Melting Temperature }\left({ }^{\circ} \mathrm{C}\right)\end{array}$

\section{Greek Symbols}

$\gamma \quad$ Volume fraction of the TCE

$k_{P C M} \quad$ Thermal Conductivity of PCMs $(\mathrm{W} / \mathrm{mK})$

$C_{\mathrm{PCM}} \quad$ Specific Heat of PCMs $(\mathrm{kJ} / \mathrm{kgK})$

$\rho_{P C M} \quad$ Density of PCMs $\left(\mathrm{kg} / \mathrm{m}^{3}\right)$

$q \quad$ Heat Flux $\left(\mathrm{kW} / \mathrm{m}^{2}\right)$

$\lambda_{P C M} \quad$ Latent Heat of PCMs (kJ/kg)

$\beta \quad$ Thermal Capacity (kJ/K) 


\section{1-Introduction}

So far, several technologies, active and passive, have been introduced for thermal management (TM) of portable electronic devices [1-4]. Previously, active TM techniques had limitations of bulky volume, noisy, more power consuming, more maintenance cost and time which eventually leads towards the inefficiency and unreliability of operation of electronic devices [5, 6]. In last few years, invention of passive cooling technologies introduced a new direction of TM of electronics using phase change materials (PCMs) and various thermal conductivity enhancers (TCEs) [1, 79]. Currently, Li et, al. [10] carried out the numerical study of a PCM filled double glazing to determine the thermophysical properties of PCM for the application of thermal energy storage. These passive cooling techniques although have taken a remarkable interest in the sight of researcher and as well as industrialist which have the tendency to compensate of all the limitations of active cooling technologies with increase in operation duration of electronic devices under user comfortable operating conditions [11-13]. However, there is the need of an optimum passive cooling device which will operate on critical design limits and enhance the operation time. In continuation of this, several studies of latent heat storage unit (LHSU) comprises of finned heat sinks as TCEs and PCMs have been reported yet [14-16]. Till yet, various configuration of fins such as square, circular, rectangular, plate, elliptical, triangular have been investigated both experimentally and numerically, however, the mostly commonly investigated pin-fin configuration was square [17-21].

Soodphakdee et, al. [17] conducted numerical study of inline and staggered circular, inline and staggered square, staggered elliptical, staggered and parallel plate-fins heat sinks. Authors concluded that staggered plate-fin showed the best heat transfer performance for provided pressure gradient and air flow rate. Nayak et, al. [22] presented the numerical model of matrix -type, platetype, rod-type thermal storage unit and found that rod-type fins performed better than in the rest of all. Jaworski [23] performed numerical study of a heat spreader made of pipes for electronics cooling. Author concluded that heat spreader had the capability to keep the temperature below $50^{\circ} \mathrm{C}$ of the microchips and protected the microprocessor from overheating while overloading of input power. Further, inclusion of heat spreader with PCM showed the excellent distribution of heat transfer in phase transition of PCM. Saha et, al. [24] carried out an optimum study for platefins and pin-fins TCEs of varying volume fractions of $0 \%, 2 \%, 8 \%, 18 \%$ and $27 \%$. The authors concluded that $8 \%$ pin-fin heat sink with $n$-eicosane has the best thermal performance. Tan and his 
co-authors [25-28] conducted the experimental studies of plate-fin PCM filled heat sinks of no fin, three number and six number of fins under power input of $3 \mathrm{~W}$ to $5 \mathrm{~W}$ and found that six numbers of plate-fin heat sink had efficient heat transfer performance from heat sink base. Baby and Balaji [29] firstly conducted experimental study between plate fin and square fin PCM based heat sinks and found square pin-fin heat sink dominated than plate-fin, further the same author in [30], they conducted an optimization study using GA-ANN and concluded that a $9 \%$ of square pin-fin configuration performed better in the rest of $4 \%$ and $15 \%$.

Baby and Balaji [31] then carried out experimental optimization study of varying volume fraction of plate-fins PCM filled heat sinks. The authors concluded a fin thickness of $1.42 \mathrm{~mm}$ having $15 \%$ volume fraction of plate-fin had the best thermal performance.

Suresh et, al.[32] conducted experimentally the comparison of four different configurations of heat sinks (empty, rectangular, square and circular) filled with paraffin wax. It was found that circular pin-fins performed better heat transfer characteristics. Similarly, Mahmoud et, al.[33] carried out experimental study of parallel and cross plate-fin of six different cavities and compared with honey comb structure heat sink and found honey comb structure gave more efficient thermal performance. Gharbi et, al. [34] conducted experimental comparison of four configuration of pure PCM, PCM in silicon matrix, PCM in graphite and PCM with plate-fins. It was found that graphite matrix with PCM had more heat transfer capability than the silicon matrix with PCM, moreover, long copper plate-fins showed the better enhancement of heat transfer from the heat sink base resulting lowering the heat sink temperature for a longer duration. Pakrouh et, al. [35, 36] performed a numerical parametric study PCM based square configuration pin-fin heat sinks. Taguchi method was adopted and parameters of number of fins, fins height, fin thickness and base thickness. Currently, the parametric investigations of square pin-fins and circular pin-fins heat sinks were presented by Arshad et, al. [37] and Ali and Arshad [38] respectively. The authors concluded that $2 \times 2 \mathrm{~mm}^{2}$ and $3 \mathrm{~mm}$ diameter had the best thermal performance individually.

From above aforementioned studies, present experimental study presents a combined comparison between $2 \mathrm{~mm}$ square and $3 \mathrm{~mm}$ circular configurations pin-fins, acting as a TCEs, heat sinks of volume fraction of $9 \%$ resulting different number of fins, filled with two different PCMs namely n-eicosane and paraffin wax having different thermo-physical properties under a range of input heat fluxes to quantify the thermal performance of passive cooling LHSU. This comparison will 
ultimately provide the better picture to the industrialist for the selection of manufacturing process and cost estimation for the mass production of novel passive technology for electronic gadgets.

\section{2-Experimental Facility}

The schematic and line diagram of experimental facility, used for current study makes up of different components, are shown in Figure 1a and 1b, respectively. There are four major parts include DC power supply [39] (Keysight Technologies 6675A, 120V/18A) with voltage and current accuracy of $0.04 \%+120 \mathrm{mV}$ and of $0.1 \%+12 \mathrm{~mA}$ respectively, latent heat storage unit (LHSU) containing high thermal conductive finned heat sinks filled with PCMs having pin-fins configuration of square and circular, Data Acquisition System (Agilent 34972A, USA) and laptop to get analog data through data acquisition system software copy righted by Agilent Technologies, Inc. Pin-fins which are acting as TCEs, have fin size of $2 \times 2 \mathrm{~mm}^{2}$ (square cross-section) and $3 \mathrm{~mm}$ diameter (circular cross-section) are used having constant volume fraction of $\gamma=9 \%$ to the overall dimension of heat sink. The volume of TCE is denoted by $\gamma$, which is the ratio of volume of fins to the total employed volume of the heat sink. Earlier, Baby and Balaji [30] carried out the optimization and found that a pin-fin heat sink of $\gamma=9 \%$ has the best thermal performance. Additionally, Arshad et, al. [37] and Ali and Arshad [38] carried the experimental studies and concluded that a pin-fin heat sink with $\gamma=9 \%$ has the best heat transfer characteristics filled with PCMs. The current study is the next step of previous experimental studies $[37,38]$, which further focuses on the comparison of obtained optimum configuration of square and circular pin-fins heat sink. The PCMs used in current study are n-eicosane [40] and paraffin wax [41], having melting temperatures of $36.5^{\circ} \mathrm{C}$ and $56-58^{\circ} \mathrm{C}$ respectively. The material of pin-fins is Aluminum (Al-T66061 ) and overall dimensions of heat sink are $114 \times 114 \times 25 \mathrm{~mm}^{3}$. To record the temperature variations at different points on the heat sinks, highly precision K-type (Omega, 0.5mm wire diameter) thermocouples are used and discrepancy error is obtained $\pm 1^{\circ} \mathrm{C}$. Calibration is carried out using ASTM standard [42] from a range of $0-100^{\circ} \mathrm{C}$. To mimic the heat generation, a silicon rubber plate heater of dimension $100 \times 100 \times 1.14 \mathrm{~mm}^{3}$ by OMEGALUX (SRFG-404/10-P-230) is adhered to the heat sinks base. A range of input constant heat densities from $1.2 \mathrm{~kW} / \mathrm{m}^{2}$ to $3.2 \mathrm{~kW} / \mathrm{m}^{2}$ with an increment of $0.4 \mathrm{~kW} / \mathrm{m}^{2}$ is supplied through plate heater. A details description 
of experimental facilities, thermos-physical properties of PCMs, see Table 1, TCEs and date reduction can been found from the previous studies of same authors [37, 38].

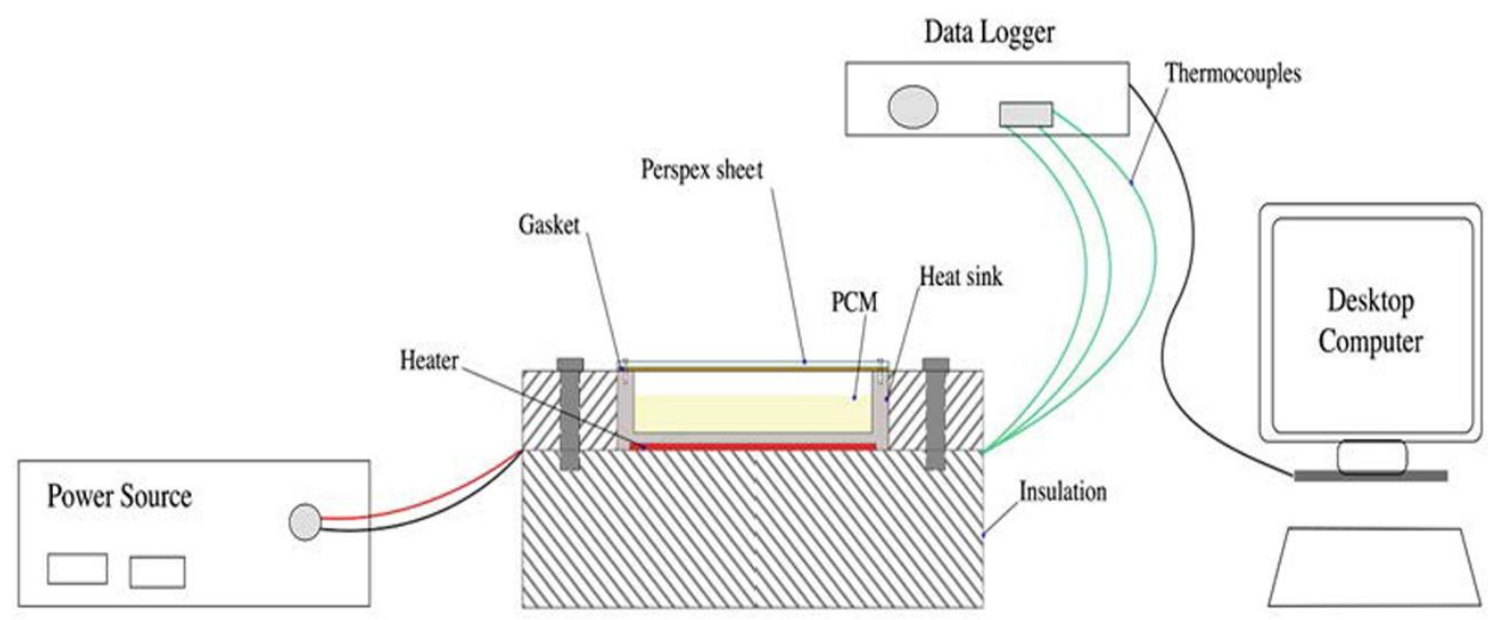

Figure 1a-Shematic diagram of experimental setup.

Table 1-Material Properties used in present study.

\begin{tabular}{|c|c|c|c|c|c|}
\hline Material & $\begin{array}{c}k_{P C M} \\
(\mathrm{~W} / \mathrm{mK})\end{array}$ & $\begin{array}{c}C_{P C M} \\
(\mathrm{~kJ} / \mathrm{kgK})\end{array}$ & $\begin{array}{c}\lambda_{P C M} \\
(\mathrm{~kJ} / \mathrm{kg})\end{array}$ & $\begin{array}{l}T_{m} \\
\left({ }^{\circ} \mathrm{C}\right)\end{array}$ & $\begin{array}{c}\rho_{P C M} \\
\left(\mathrm{~kg} / \mathrm{m}^{3}\right)\end{array}$ \\
\hline \multirow{2}{*}{ Paraffin Wax } & 0.167 (Liquid) & \multirow{2}{*}{2.8} & \multirow{2}{*}{173.6} & \multirow{2}{*}{$56-58$} & 790(Liquid) \\
\hline & 0.212 (Solid) & & & & 880 (Solid) \\
\hline \multirow{2}{*}{ n-Eicosane } & 0.160 (Liquid) & 2.2(Liquid) & \multirow{2}{*}{237.4} & \multirow{2}{*}{36.5} & 780(Liquid) \\
\hline & 0.40 (Solid) & 1.9(Solid) & & & 820(Solid) \\
\hline Aluminum & 202.37 & 0.871 & & 660.37 & 2719 \\
\hline Rubber Pad & 0.043 & 1.23 & & - & 2500 \\
\hline
\end{tabular}




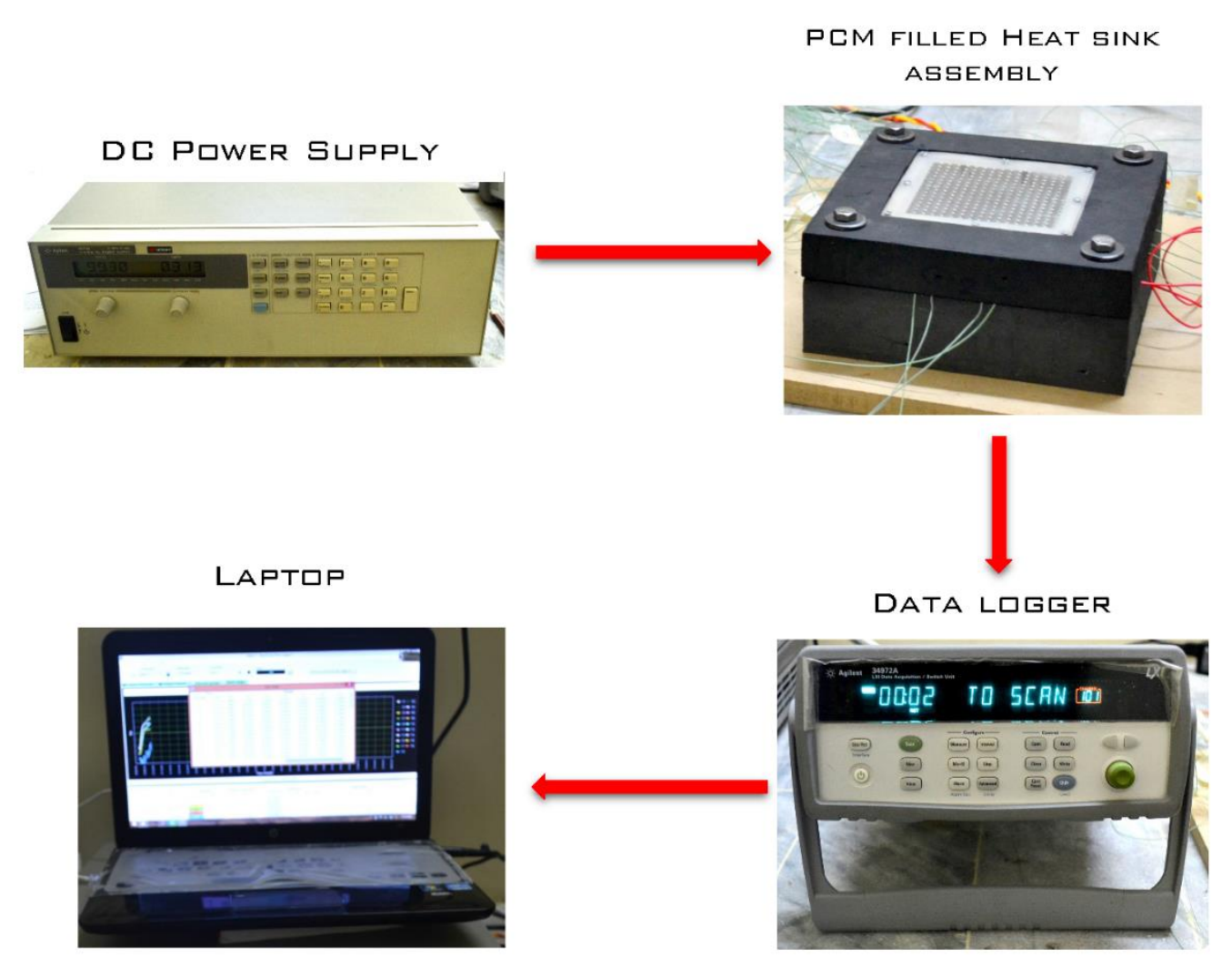

Figure $1 b$-Line flow of experimental facility.

\section{3-Results and Discussions}

The results are incorporating the geometrical and thermally comparison of $2 \mathrm{~mm}$ and $3 \mathrm{~mm}$ pinfins heat sink embedded with PCMs paraffin wax and n-eicosane. The details are following in different sections to explore the thermal characteristics of both pin-fins geometries heat sinks.

\section{1-Comparison of Heat Sinks base temperatures}

The comparison of heat sinks base temperatures (recorded by the thermocouples $\mathrm{H} 1, \mathrm{H} 2$ and $\mathrm{H} 3$ ) for input heat fluxes of $2.0 \mathrm{~kW} / \mathrm{m}^{2}$ and $2.8 \mathrm{~kW} / \mathrm{m}^{2}$ are shown in Figure $2 \mathrm{a}-2 \mathrm{~b}$ for PCMs paraffin wax and n-eicosane. In both figures, it can be seen ultimately that the $3 \mathrm{~mm}$ circular configuration pin-fin heat sink leads to lower the base temperature significantly in comparison of $2 \mathrm{~mm}$ square configuration pin-fin heat sink particularly in case of paraffin wax but closely for n-eicosane. However, the closer look at the peak temperatures reveals that $3 \mathrm{~mm}$ pin-fin heat sink has maximum and best thermal performance for passive cooling of electronics embedded with PCMs. The temperature curves are overlapping initially for both PCMs, in both figures, however for 
paraffin wax, $3 \mathrm{~mm}$ thick round pin-fin clearly manifests better heat transfer than $2 \mathrm{~mm}$ fin thickness square pin-fin. The uniform temperature distribution from heat sink base to PCMs through fins is solely depends on number of fins and pitch of fins (the fin spacing in stream-wise, span-wise and diagonal directions).

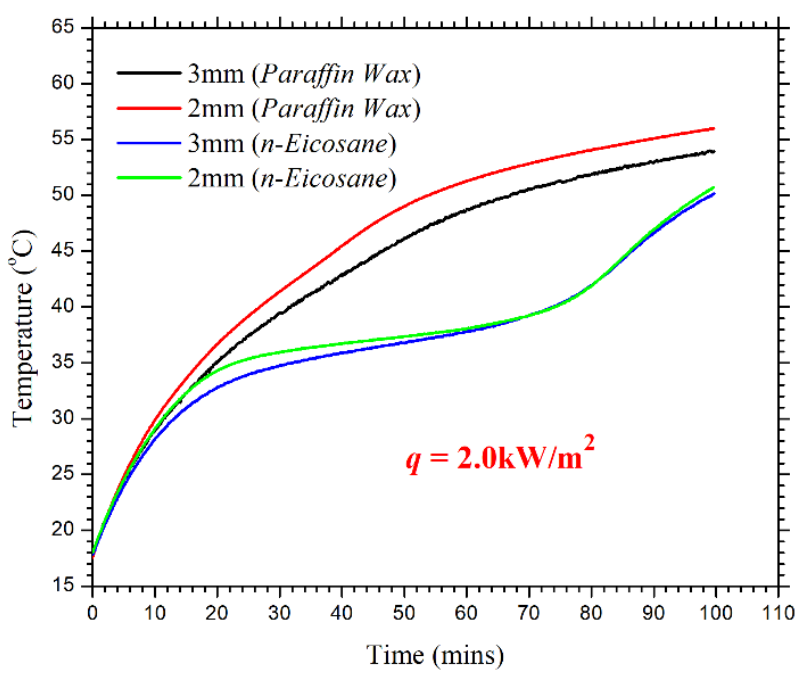

Figure 2-(a)

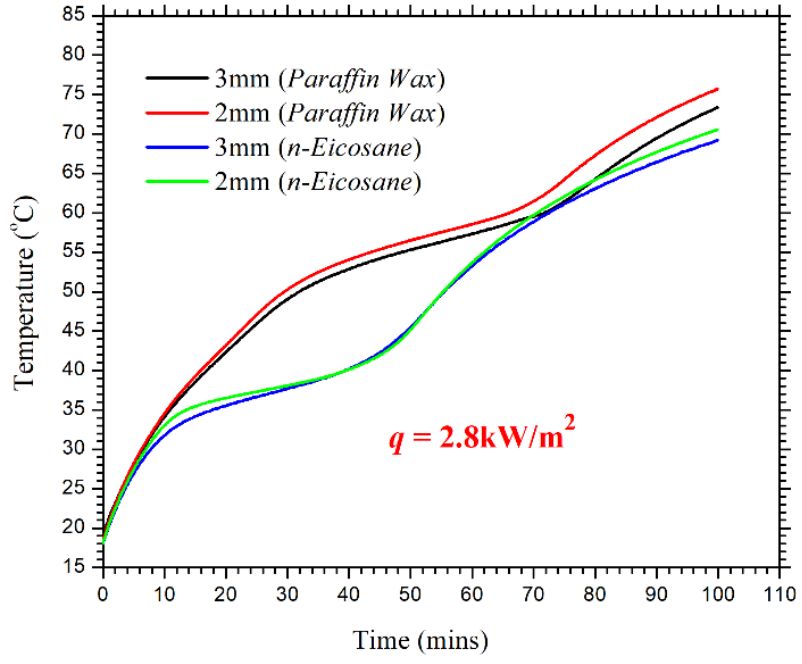

Figure 2-(b)

Figure 2-Comparison of heat sinks base temperature for paraffin wax and n-eicosane. (a) $q=2.0 \mathrm{~kW} / \mathrm{m}^{2}(\mathrm{~b}) q=2.8 \mathrm{~kW} / \mathrm{m}^{2}$

\section{2-Comparsion of Latent Heating Phase duration}

The comparison of latent heat phase completion time is shown in Figure 3. The range of input heat fluxes are provided from $1.2 \mathrm{~kW} / \mathrm{m}^{2}$ to $2.8 \mathrm{~kW} / \mathrm{m}^{2}$ with an interval of $0.4 \mathrm{~kW} / \mathrm{m}^{2}$. The comparison of $3 \mathrm{~mm}$ circular and $2 \mathrm{~mm}$ square cross-sectional thick pin-fin heat sinks clearly evidences that the $3 \mathrm{~mm}$ thick circular pin-fin heat sink leads from the $2 \mathrm{~mm}$ thick square pin-fin configuration heat sink to enhancing the latent heat phase duration. The two extreme, maxima and minima, latent heating phase completion times of $141 \mathrm{mins}$ and $36 \mathrm{mins}$ are obtained at $1.2 \mathrm{~kW} / \mathrm{m}^{2}$ and $2.8 \mathrm{~kW} / \mathrm{m}^{2}$ input heat densities for $3 \mathrm{~mm}$ thick circular pin-fin heat sink. The enhanced latent heating phase duration is because of optimum fins distribution which transfer the internal generated heat more uniformly through fins without causing local overheating the heat sink base. 


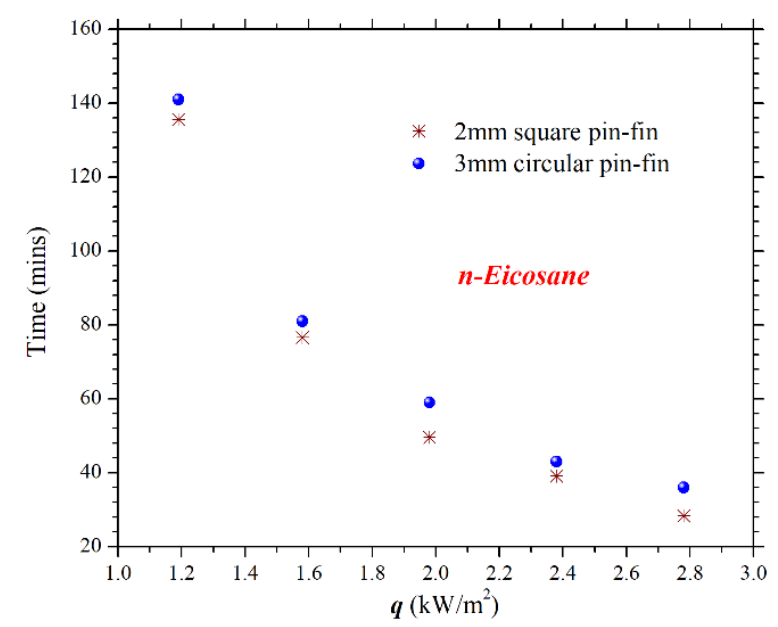

Figure 3-comparison of latent heating phase completion time.

\section{3-Comparion of Enhancement in Operation time}

The thermal performance of both tested pin-fin heat sinks is terms of enhancement in operation times is presented in Figure 4a-4b for employed PCMs, paraffin wax and n-eicosane respectively. Operation time, actually is the maximum operating duration at which the cooling device can sustain its work operation under reliable conditions without causing any harm and losing its efficiency. In current experimentation, two SPTs $65^{\circ} \mathrm{C}$ and $45^{\circ} \mathrm{C}$ are chosen as per melting temperatures of paraffin wax and n-eicosane, given in Table 1, to compare the time taken by $3 \mathrm{~mm}$ circular and $2 \mathrm{~mm}$ square fin thickness heat sinks to reach at these SPTs. The results shown in both Figures it can be clearly evidenced that the $3 \mathrm{~mm}$ thick pin-fin heat sink of circular cross-section takes more time to reach for either of SPT $=65^{\circ} \mathrm{C}$ or SPT $=45^{\circ} \mathrm{C}$. This shows that a pin-fin heat sink of $3 \mathrm{~mm}$ fin diameter has maximum tendency to store heat, generated inside the electronic device, and transfer it atmosphere which eventually leads to cool down the electronic device temperature in comfortable zone for end users. 


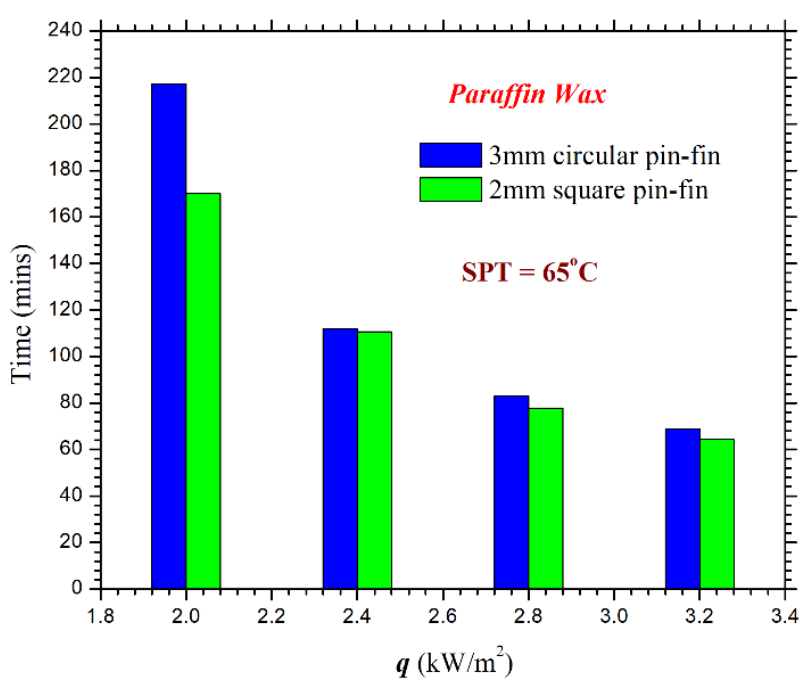

Figure 4-(a)

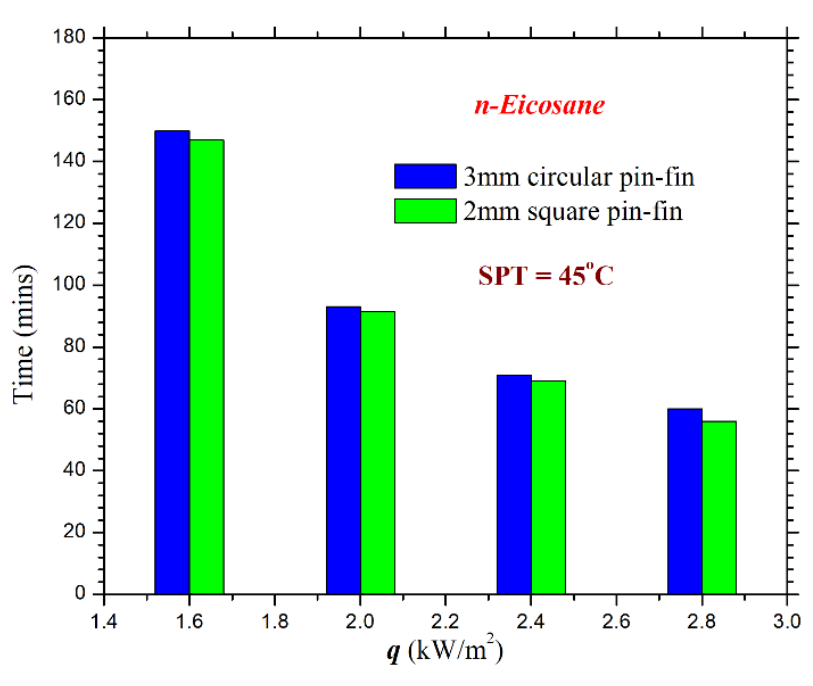

Figure 4-(b)

Figure 4-Comparison of enhancement in operation time. (a) $S P T=65^{\circ} \mathrm{C}$ (b) $S P T=45^{\circ} \mathrm{C}$.

\section{4-Comparion of Thermal Capacity and Thermal Conductance}

The comparisons of thermal properties (i.e. thermal capacity and thermal conductance) of $3 \mathrm{~mm}$ and $2 \mathrm{~mm}$, circular and square configuration respectively, pin-fin heat sinks are presented in Figures 5a-5b and Figure 6. A higher thermal capacity reflects that the system needs higher thermal energy to rise its temperature which eventually enhance the cooler time in operation mode. The maximum thermal capacities of $2.24 \mathrm{~kJ} / \mathrm{K}$ and $2.90 \mathrm{~kJ} / \mathrm{K}$ are obtained for $3 \mathrm{~mm}$ thick circular pinfin heat sink for n-eicosane as a PCM at input heat flux of $2.0 \mathrm{~kW} / \mathrm{m}^{2}$. However, for paraffin wax at $2.0 \mathrm{~kW} / \mathrm{m}^{2}$, a thermal capacity of $3.08 \mathrm{~kJ} / \mathrm{K}$ is found for $3 \mathrm{~mm}$ thick circular pin-fin heat sink. Similarly, from Figure 6, the thermal conductance of $6.95 \times 10^{-1} \mathrm{~W} / \mathrm{K}$ and $5.69 \times 10^{-1}$ are obtained for paraffin wax and n-eicosane respectively in case of $3 \mathrm{~mm}$ thick circular pin-fin heat sink. Thermal conductance which is heat transfer rate per unit temperature difference from the surface of PCM filled heat sink to the ambient conditions. From figures 5a-5ba and 6, it is revealed that the best thermal performance of $3 \mathrm{~mm}$ circular pin-fin heat sink is because of optimum number of fins, fin thickness, fins pitch. 


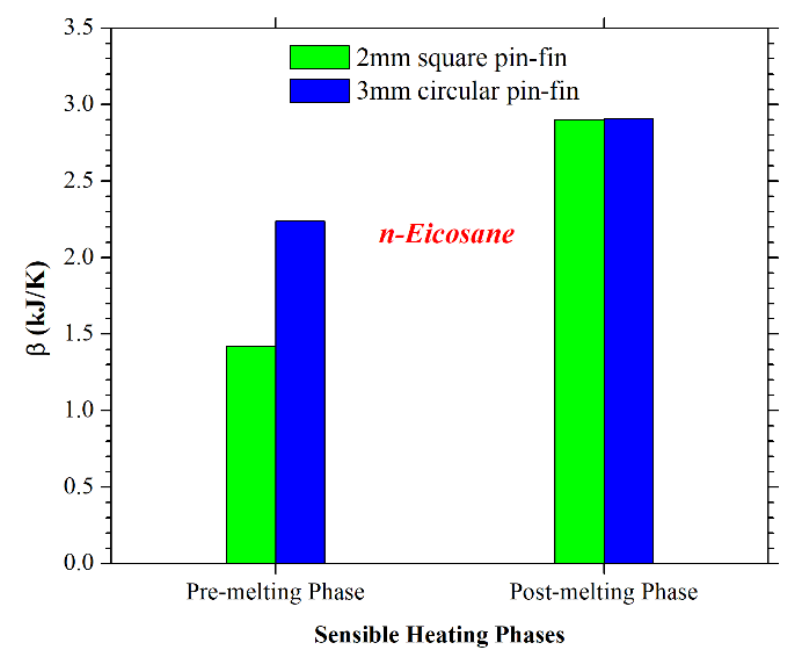

Figure 5-(a)

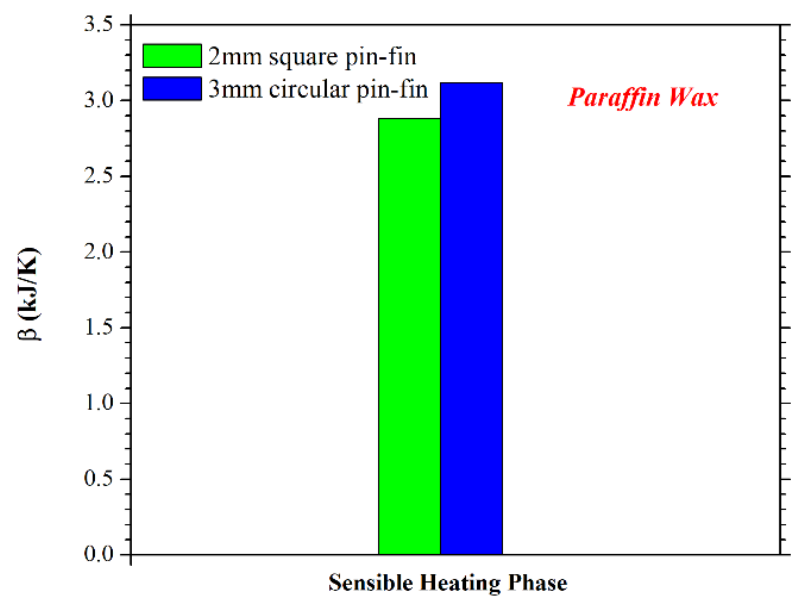

Figure 5-(b)

Figure 5-Comparison of thermal capacity of heat sinks (a) n-eicosane (b) paraffin wax

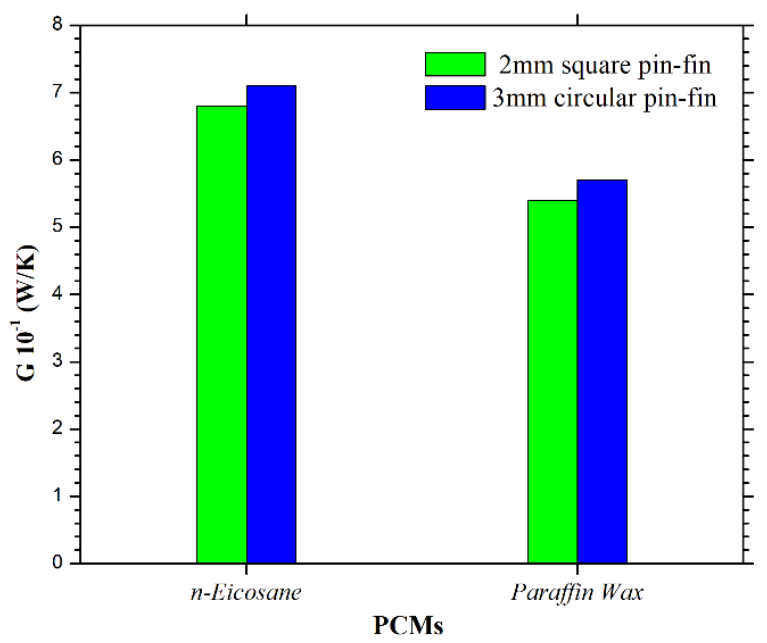

Figure 6-Comparison of thermal conductance of heat sinks for paraffin wax and n-eicosane. 


\section{Conclusion}

A comparison of two different configurations (square and circular) pin-fin heat sinks embedded with two different PCMs namely paraffin wax and n-eicosane having different thermo-physical properties were carried out for passive cooling of electronic devices. The pin-fins, acting as TCEs, of $2 \mathrm{~mm}$ square and $3 \mathrm{~mm}$ circular fin thickness of constant volume fraction of $9 \%$ are chosen and input heat fluxes from $1.2 \mathrm{~kW} / \mathrm{m}^{2}$ to $3.2 \mathrm{~kW} / \mathrm{m}^{2}$ with an increment of $0.4 \mathrm{~kW} / \mathrm{m}^{2}$ are provided. The results found the following conclusions;

1. The comparison of heat sinks base temperature proves that $3 \mathrm{~mm}$ diameter of pin-fin heat sink better than $2 \mathrm{~mm}$ square pin-fin heat sink.

2. An enhancement in operation times of 210mins for paraffin wax and 150mins for $n$ eicosane are found at input heat flux of $2.0 \mathrm{~kW} / \mathrm{m}^{2}$ and $1.6 \mathrm{~kW} / \mathrm{m}^{2}$ respectively. Similarly, higher operations times to reach SPTs of $65^{\circ} \mathrm{C}$ and $45^{\circ} \mathrm{C}$ are found for $3 \mathrm{~mm}$ circular configuration pin-fin heat sink in comparison of $2 \mathrm{~mm}$ square configuration fin thickness pin-fin heat sink.

3. In continuation, of comparing both configurations pin-fin heat sinks filled with n-eicosane the maximum latent heat phase completion time are found for $3 \mathrm{~mm}$ thick circular pin-fin heat sink for all provided input heat fluxes. The maximum and minimum latent heat phase completion duration are found of $141 \mathrm{mins}$ and $36 \mathrm{mins}$ at $1.2 \mathrm{~kW} / \mathrm{m}^{2}$ and $2.8 \mathrm{~kW} / \mathrm{m}^{2}$ input heat densities for $3 \mathrm{~mm}$ diameter pin-fin heat sink.

4. The comparison of thermal capacities and thermal conductance further proves that $3 \mathrm{~mm}$ diameter fin thickness pin-fin heat sink has maximum potential to absorb thermal energy and to transfer heat from the electronic devices.

To sum up, the above findings reveals that a $3 \mathrm{~mm}$ fin diameter circular pin-fin heat sink filled with PCMs namely paraffin wax or n-eicosane has maximum tendency of an efficient and reliable passive thermal management technology for electronic devices. 


\section{List of Figures}

Figure 1-Line flow of experimental facility.

Figure 2-Comparison of heat sinks base temperature for paraffin wax and n-eicosane. (a) $q=2.0 \mathrm{~kW} / \mathrm{m}^{2}$ (b) $q=$ $2.8 \mathrm{~kW} / \mathrm{m}^{2}$

Figure 3-comparison of latent heating phase completion time.

Figure 4-Comparison of enhancement in operation time. (a) $S P T=65^{\circ} \mathrm{C}$ (b) $S P T=45^{\circ} \mathrm{C}$.

Figure 5-Comparison of thermal capacity of heat sinks (a) n-eicosane (b) paraffin wax

Figure 6-Comparison of thermal conductance of heat sinks for paraffin wax and n-eicosane.

\section{List of Tables}

Table 1-Material Properties used in present study. 


\section{References:}

1. Sahoo, S.K., M.K. Das, and P. Rath, Application of TCE-PCM based heat sinks for cooling of electronic components: A review. Renewable and Sustainable Energy Reviews, 2016. 59: p. 550-582.

2. Zhang, H., et al., Free cooling of data centers: A review. Renewable and Sustainable Energy Reviews, 2014. 35: p. 171-182.

3. Walsh, E., et al., Thermal management of low profile electronic equipment using radial fans and heat sinks. Journal of heat transfer, 2008. 130(12): p. 125001.

4. Walsh, E. and R. Grimes, Low profile fan and heat sink thermal management solution for portable applications. International Journal of Thermal Sciences, 2007. 46(11): p. 11821190.

5. Ali, H.M. and W. Arshad, Thermal performance investigation of staggered and inline pin fin heat sinks using water based rutile and anatase TiO2 nanofluids. Energy Conversion and Management, 2015. 106: p. 793-803.

6. Ali, H.M., M.U. Sajid, and A. Arshad, Heat Transfer Applications of TiO2 Nanofluids, in Application of Titanium Dioxide, M. Janus, Editor. 2017, InTech: Rijeka. p. Ch. 09.

7. Wirtz, R.A., N. Zheng, and D. Chandra, Thermal management using "Dry" phase change materials., in Fifteenth IEEE SEMI-THERMSymposium1999. p. 74-82.

8. Vesligaj, M.J. and C.H. Amon, Transient thermal management of temperature fluctuations during time varying workloads on portable electronics. IEEE Transactions on Components and Packaging Technologies, 1999. 22(4): p. 541-550.

9. Thomas, J., et al., Thermal Performance Evaluation of a Phase Change Material Based Heat Sink: A Numerical Study. Procedia Technology, 2016. 25: p. 1182-1190.

10. Li, D., et al., Thermal performance of a PCM-filled double-glazing unit with different thermophysical parameters of PCM. Solar Energy, 2016. 133: p. 207-220.

11. Ahmed, T., et al. Experimental Investigation of Thermal Management of Tablet Computers using Phase Change Materials (PCMs). in Proc. of the ASME 2016 Summer Heat Transfer Conference. 2016.

12. Yang, Y.-T. and Y.-H. Wang, Numerical simulation of three-dimensional transient cooling application on a portable electronic device using phase change material. International Journal of Thermal Sciences, 2012. 51: p. 155-162.

13. Tomizawa, Y., et al., Experimental and numerical study on phase change material (PCM) for thermal management of mobile devices. Applied Thermal Engineering, 2016. 98: p. 320-329.

14. Alawadhi, E.M. and C.H. Amon, PCM Thermal Control Unit for Portable Electronic Devices: Experimental and Numerical Studies, in IEEE Transactions on components and packaging technologies.2003. p. 116-125.

15. Baby, R. and C. Balaji, Thermal management of electronics using phase change material based pin fin heat sinks, in 6th European Thermal Sciences Conference,Journal of Physics 2012, IOP Publishing.

16. Baby, R. and C. Balaji, Thermal performance of a PCM heat sink under different heat loads: An experimental study. International Journal of Thermal Sciences, 2014. 79: p. 240249.

17. Soodphakdee, D., Behnia, M., \& Copeland, D. W., A Comparison of Fin Geometries for Heatsinks in Laminar Forced Convection-Part I: Round, Elliptical, and Plate Fins in 
Staggered and In-Line Configurations. Int. J. Microcircuits Electron. Packag, , 2001. 24(1): p. 68-76.

18. Wang, Y.-H. and Y.-T. Yang, Three-dimensional transient cooling simulations of a portable electronic device using PCM (phase change materials) in multi-fin heat sink. Energy, 2011. 36(8): p. 5214-5224.

19. Wang, X.-Q., C. Yap, and A.S. Mujumdar, A parametric study of phase change material (PCM)-based heat sinks. International Journal of Thermal Sciences, 2008. 47(8): p. 10551068.

20. Shang, B., et al., Passive thermal management system for downhole electronics in harsh thermal environments. Applied Thermal Engineering, 2017. 118: p. 593-599.

21. Ashraf, M.J., et al., Experimental passive electronics cooling: Parametric investigation of pin-fin geometries and efficient phase change materials. International Journal of Heat and Mass Transfer, 2017. 115, Part B: p. 251-263.

22. Nayak, K.C., et al., A numerical model for heat sinks with phase change materials and thermal conductivity enhancers. International Journal of Heat and Mass Transfer, 2006. 49(11-12): p. 1833-1844.

23. Jaworski, M., Thermal performance of heat spreader for electronics cooling with incorporated phase change material. Applied Thermal Engineering, 2012. 35: p. 212-219.

24. Saha, S.K., K. Srinivasan, and P. Dutta, Studies on Optimum Distribution of Fins in Heat Sinks Filled With Phase Change Materials. Journal of Heat Transfer, 2008. 130(3): p. 034505.

25. Tan, F.L. and C.P. Tso, Cooling of mobile electronic devices using phase change materials. Applied Thermal Engineering, 2004. 24(2-3): p. 159-169.

26. Setoh, G., F.L. Tan, and S.C. Fok, Experimental studies on the use of a phase change material for cooling mobile phones. International Communications in Heat and Mass Transfer, 2010. 37(9): p. 1403-1410.

27. Fok, S.C., W. Shen, and F.L. Tan, Cooling of portable hand-held electronic devices using phase change materials in finned heat sinks. International Journal of Thermal Sciences, 2010. 49(1): p. 109-117.

28. Hosseinizadeh, S.F., F.L. Tan, and S.M. Moosania, Experimental and numerical studies on performance of PCM-based heat sink with different configurations of internal fins. Applied Thermal Engineering, 2011. 31(17-18): p. 3827-3838.

29. Baby, R. and C. Balaji, Experimental investigations on phase change material based finned heat sinks for electronic equipment cooling. International Journal of Heat and Mass Transfer, 2012. 55(5-6): p. 1642-1649.

30. Baby, R. and C. Balaji, Thermal optimization of PCM based pin fin heat sinks: An experimental study. Applied Thermal Engineering, 2013. 54(1): p. 65-77.

31. Baby., R. and C. Balaji., A Neural Network-Based Optimization of Thermal Performance of Phase Change Material-Based Finned Heat Sinks-An Experimental Study. Experimental Heat Transfer: A Journal of Thermal Energy Generation, Transport, Storage, and Conversion, 2013. 26(5): p. 431-452.

32. Suresh, S., et al., Experimental investigaion of PCM-based heat sink with differnt configuratio ns of internal fins., in International Conference on Advance Research in Mechanical, Aeronautical And Civi2013: Pattaya. p. 54-59. 
33. Mahmoud, S., et al., Experimental investigation of inserts configurations and PCM type on the thermal performance of PCM based heat sinks. Applied Energy, 2013. 112: p. 13491356.

34. Gharbi, S., S. Harmand, and S.B. Jabrallah, Experimental comparison between different configurations of PCM based heat sinks for cooling electronic components. Applied Thermal Engineering, 2015. 87: p. 454-462.

35. Pakrouh, R., et al., A numerical method for PCM-based pin fin heat sinks optimization. Energy Conversion and Management, 2015. 103: p. 542-552.

36. Pakrouh, R., M.J. Hosseini, and A.A. Ranjbar, A parametric investigation of a PCM-based pin fin heat sink. Mechanical Sciences, 2015. 6(1): p. 65-73.

37. Arshad, A., et al., Thermal performance of phase change material (PCM) based pin-finned heat sinks for electronics devices: Effect of pin thickness and PCM volume fraction. Applied Thermal Engineering, 2017. 112: p. 143-155.

38. Ali, H.M. and A. Arshad, Experimental investigation of n-eicosane based circular pin-fin heat sinks for passive cooling of electronic devices. International Journal of Heat and Mass Transfer, 2017. 112: p. 649-661.

39. Keysight Technologies, I.; Available from: http://www.keysight.com/en/pd-839012-pn$6675 \mathrm{~A} / 2000$-watt-system-power-supply-120v-18a?cc=PK\&lc=eng.

40. Sigma-Aldrich. Sigma-Aldrich 3050 Spruce St. Louis, MO 63103. . 2016; Available from: http://www.sigmaaldrich.com/catalog/product/aldrich/219274?lang=en\&region=US.

41. EMD Millipore is a part of Merck KGaA, D., Germany. 2016; Available from: http://www.emdmillipore.com/US/en/product/Histosec-pastilles,MDA_CHEM-111609.

42. Taylor, B.N. and C.E. Kuyatt, Guidelines for evaluating and expressing the uncertainty of NIST measurement results. 1994: US Department of Commerce, Technology Administration, National Institute of Standards and Technology Gaithersburg, MD. 